\title{
Non-Profit Organizations' Financial Governance Research
}

\author{
Hong-juan Wang \\ The department of Economics and Management, Linyi University, Linyi, Shandong, China
}

\begin{abstract}
From the non-profit organization's financial governance theory, this article analyzes related issues to the financial governance theory in the application of non-profit organizations, puts forward to the corresponding solution, aiming to make faster and better development toward the direction of health and better services for the society.
\end{abstract}

Keywords-Governance, Financial governance, Non-profit organizations

\section{非营利组织财务治理研究}

\author{
王红娟 \\ 临沂大学经管学部, 临沂, 山东, 中国
}

\begin{abstract}
摘 要 文章从非营利组织的财务治理理论出发, 通过对比营利组织与非营利组织的差异, 发现非营利组织的财务治理存在的问 题, 提出相应的解决措施, 目的在于使非营利组织向着更快更好的方向健康地发展, 更好地为社会进行服务。
\end{abstract}

关键词 治理, 财务治理, 非营利组织

\section{1. 财务治理理论与非营利组织概述}

\section{1 财务治理理论}

\section{1 .1 治理}

治理是普遍应用于政治经济学领域内的一个术语, 意 思是“统治”。奥立弗. 哈特认为, 一个组织只要存在以下条 件时就会产生治理问题: 第一代理问题, 在信息不对称时, 对于存在交易的双方来说, 掌握信息多的一方就有可能欺 骗掌握信息少的一方以谋取私利; 第二合同不完全, 因为 周围环境的不确定性和人的有限理性, 人们之间不可能签 订一个可以解决所有问题的合同或虽能签订但要花费较高 的交易成本。因此这就要设计一个合理的治理结构, 以决 定如何分配剩余控制权。

\subsection{2 财务治理}

它是从所有权和控制权分离的现代企业制度中产生 的, 其实质上是一种财务权限划分, 实现剩余控制权和剩 余要求权之间的合理配置, 从而形成良好的激励约束机制、 制衡机制。财务治理可以归结为: 财务治理是在当前公司 制环境下, 政府、出资人和经营管理者之间在财务收支管 理、财务剩余索取、财务监督、财务利益分配和财务人员 配置等各方面权限的划分, 从而形成相互制衡关系的财务
管理体制。

\section{2 非营利组织}

非营利组织是在政府失灵和市场失灵的前提下产生 的, 其出现被视为是一种制度的创新。在政府失灵和市场 失灵的某些特殊领域如教育科研, 非营利组织确实是一种 比较有效的制度形式。从整个社会来看, 社会组织可以分 为三大部门: 第一部门---企业, 第二部门---政府, 第三部 门---非营利组织, 由此也形成了现代社会所谓的 “三元结 构”。

关于非营利组织的定义, 较为流行的是美国约翰---霍 普金斯大学莱斯特. 萨拉蒙（Lester Salamon,1993）教授提 出的所谓五特征性: 组织性、非政府性、非营利性、自治 性、志愿性。非营利组织是指不以获取利润为目的, 为社 会公益服务的, 提供准公共产品的独立部门。

\section{3 非营利组织财务治理}

非营利组织是一种创新制度形式, 具有相对较低的交 易费用, 它通过接受社会捐赠作为其主要的资金来源, 以 社会公益人的身份在某些特殊领域提供公共产品或服务。 


\section{2. 非营利组织财务治理存在的问题}

在非营利组织内不存在剩余要求权, 也就是说没有人 可以公开宣称享有剩余要求权, 由此对非营利组织财务治 理研究构成了新的障碍。它不能完全遵循营利组织财务治 理的研究思路和成果, 需要在借鉴的基础上有所创新。

\section{1 资金来源及运用单一}

非营利组织的主要资金来源方式包括：捐赠、政府资 助、会员会费等, 很少有市场收入, 这和非营利组织的非 营利性密切相关。因此, 与营利组织形成明显的区别, 营 利组织主要的资金来源是通过销售产品和服务, 从顾客那 里获取相应的销售收入和劳务收入, 它是一种有偿收入。

非营利组织的支出分为项目及活动支出和行政支出。 这里的支出与营利组织不同, 营利组织支出即投资是为了 获得经济上的利益, 投资的管理必须从经济效益出发, 随 着经济环境的恶化, 营利组织在经济效益的基础上, 越来 越重视社会效益、生态效益, 而非营利组织其支出注重的 是社会效益, 是单一的效益。

\section{2 财务制度的缺失}

(1)绩效缺少可比性。在营利组织财务中, 利润指标能 为衡量企业绩效提供标准, 为营利组织提供量化分析的方 法, 便于在不同组织之间进行比较。然而, 非营利组织是 不以获取利润为目的的为社会公益服务的组织, 在其财务 中通常缺少利润这一指标, 这样不同非营利组织之间无法 进行绩效的对比。

(2)单一的所有权形式。对营利组织而言, 股东 (或投 资者) 为营利组织的所有者, 拥有其权益, 在营利组织实 现利润时, 能相应获得一定的回报。非营利组织的权益属 于组织本身所与, 而且资财提供者不期望收回或者取得经 济上的利益, 因此通常不进行损益的计算, 也不进行净收 入的分配。

(3)财务报告的重要性不明显。相当多的非营利组织如 无特殊情况不作年度财务报告, 或虽作年度财务报告但无 严格审计, 财务报告资源缺少透明度, 这与营利组织的年 度财务报告定期编制, 及时对外报送, 定期、不定期进行 审计, 资源透明度形成明显的对比。

(4)财务目标不一致。由于信息不对称, 非营利组织的 委托人难以准确判断代理人采取机会主义行为的可能性, 代理人的财务行为可能偏离社会公益最大化的组织宗旨, 这样就违背了非营利组织的财务治理目标。相比之下, 营 利组织代理人的报酬所得和公司的经营成果息息相关, 所 以代理人就会为公司的财富最大化而努力的, 不会违背公
司的财务治理目标。

\section{3 信息批露的动力不足}

非营利组织财务治理中最主要的议题就是委托---代 理。该问题相对于非营利性组织而言, 存在如下特点:

(1)产出没有明确的市场价格。在营利组织中, 产出的 定价是根据供给和需求的均衡原理来确定产出的价格; 而 在非营利组织中, 产出即准公共产品是用来进行服务的, 又不能以利润最大化作为自己的目标, 这样导致了产出的 市场价格不确定。

(2)成本核算的动力不足。产出具有公共服务的性质, 其品质和数量难以低成本准确测量。在营利组织中, 通过 生产产品的直接消耗和间接消耗先在制造费用中进行归 集, 然后通过一定的分配方法分配到单个产品成本中去, 用来计算产品的成本。非营利组织的运营不以营利为目的, 其所耗费的资源主要不是靠自身的投入，而是由政府拨款 或捐赠人捐赠获得资金，而资财提供者不要求取得经济回 报, 政府及出资人不需要非营利组织提供利润信息, 所以 也就没有核算成本的外部压力。

(3)监督主体动力不足。缺少可让渡的剩余要求权, 致 使监督主体的动力不足, 偷懒行为较严重, 也使管理者可 免遭外部市场竞争者的驱逐。由于资源提供者放弃了对资 源的捐赠及其收益的要求权, 与剩余要求者提供资源的组 织对比, 监督主体的动力不足, 由此导致管理者也会偷懒, 不会全心全力的来管理组织。

(4)评价标准不明确, 很难以确切的财务指标体系进行 量化。其一, 非营利组织没有利润指标, 其二其很少会去 考虑产出的成本, 尤其是如何降低成本。成本和利润这两 个较简单的财务指标都不存在, 更不用谈其他引申的财务 指标及相应的财务指标体系。

\section{4 财权配置是非营利组织财务治理的基础}

财权是派生于产权的财务权力, 是体现一定财务经济 关系的一组权力束, 大体包括财务决策权、收益分配和监 督等职能。当出资者将其财产投入现代公司时, 各种财产 就形成了法人财产由企业法人进行使用、管理等。对于非 营利组织, 资源提供者将财产投入组织后, 便失去了财产 的所有权, 不享受对应的权益及受益权。财产受托人拥有 和支配这些财产, 只有支配意义上的控制权。由于社会公 益性的存在, 非营利组织的受益人也就拥有了财产益权。 在财权上存在着所有权、控制权与受益权的“三权分离”问 题。 


\section{3. 针对以上问题提出相应的解决措施}

\section{1 完善的财务治理系统}

非营利组织组织内都存在复杂的委托代理关系, 具有 科层结构特征, 疏于内部控制, 必然造成内部治理成本过 度膨胀。完善的财务治理系统有助于在非营利组织内部营 造一种管理规范, 形成持续发展的良好机制, 将是非营利 组织降低消耗、提高效率、增加产出的有效手段。现代的 财务治理系统可以从以下两个方面进行研究, 一是有效的 财务治理结构, 二是完善的财务治理机制。

建立内部控制时, 可以在一段时间内逐步建立成熟、 完善的财务治理结构, 加强内部控制。一般来讲, 公益性 非营利组织的财务治理结构由会员代表大会、理事会、经 理层与监事会等组成。当然, 在非营利组织不同的发展阶 段, 其良好财务治理结构的建立可能会有所不同, 有所侧 重, 这都是任何一个组织在发展过程中不可避免的。现代 内部控制主要是通过目标激励机制来实现。一种有效的激 励机制包含正向激励与反向约束两个方面, 对于组织目标 的行为给予适时的奖励和惩罚。

所有的公益性非营利组织共同努力的奋斗目标就是要 建立完善的财务治理机制, 加强内部控制。完善的财务治 理机制与现实的公益性非营利组织也许还有一段距离要 走, 但我们要坚持这一目标。公益性非营利组织的财务治 理机制一般包括财务决策、监督与评价机制三个方面, 从 事前、事中、事后三个角度对非营利组织资源的取得和使 用情况加强管理, 保证决策、执行与监督的分离, 实现决 策权、执行权与监督权的三权分离, 确保非营利组织应对 重大事项、一般事项和基础性事项时的决策效率及决策的 正确性, 通过完善内部控制机制, 在非营利组织内部建立 覆盖所有职能部门、所有业务环节、所有工作岗位、所有 工作人员的协调和控制机制。

\section{2 完善的信息批露}

信息披露是非营利组织财务治理的重要工具。一是信 息披露可以提高财务信息在组织内、外部利益相关者之间 的分享度, 提高其信息透明度; 二是信息披露的准确、及 时关系到利益相关者能否进行正确的财务决策; 三是信息 披露构成了财务监督的一个重要组成部分。在所有权与经 营权的分离所产生的委托---代理制度中, 代理人享有经营 管理财务的权力, 这时, 信息披露对所有权的权力行使与 保证就非常重要。非营利组织行为源于信息不对称, 其特 性决定了该组织不应该设有秘密, 为此尽最大可能的进行 信息批露是其应尽的义务。非营利组织必须全方位的向社 会公众批露其相关营运活动的信息, 尤其是财务信息。财
务有了较好的透明度就会拥有更多的社会公信度, 就可以 为组织赢得更多的资金。为此, 我国的非营利组织就要有 动力进行财务报告的编制, 有必要对其进行外部的审计, 保证财务监督权的实现。建立完善的信息批露制度, 是非 营利组织可持续发展的必然要求。这样不仅为其提高了社 会公信力, 而且为其资金来源的进一步扩大奠定了基础。

\section{3 建立合适的财务指标及相应的指标体系}

根据非营利组织的特点, 可以设计一些反映其财务风 险的指标。例如, 第一, 公益支出率 (公益支出/公益收入 总额), 它考核在一定时期内, 有多少公益资金用在了社会 公益上; 第二，公益资金投资比（对外投资额/公益资金总 额), 它用于考核在一定时期内, 有多少资金用在了对外投 资上。当然, 为了反映非营利组织的财务状况, 也可从不 同的角度建立非营利组织的财务分析体系, 体现财务治理 的效果。当然为了提高非营利组织财务运行绩效, 非营利 组织财务管理乃至整个经济活动都可以引进和借鉴绩效管 理等企业管理方法, 建立有效的绩效预算考评体系, 根据 预算落实和执行情况, 按年终决算结果进行绩效考评, 既 提高管理者的积极性，也保证了预算资金的高效使用。采 取措施提高非营利组织的筹资和增值能力, 解决组织资金 的供给问题。通过市场化运作方式, 争取更多的慈善捐款, 充分利用闲置资金，提高资金的使用效率。

\section{4 健全职业道德建设}

职业道德责任存在于非营利组织的各个成员的天性 中, 是绝对责任在实践中的应用和体现。为了公共利益、 大家利益、每个人的利益, 唤起每个人的志愿公益精神, 是我国非营利组织发展过程中非常重要的工作。职业道德 要求员工在本职工作中不怕艰苦, 勤奋工作, 既讲团结协 作, 又论个人贡献, 既讲经济效益, 又讲社会效益。加强 职业道德建设, 就要紧密联系本行业本单位的实际, 以“为 人民服务, 对人民负责” 为准绳, 有针对性地解决非营利组 织中实际存在的问题, 使组织真正成为一个具有社会主义 精神风貌的和谐集体。这既能保持科学的发展观, 促进社 会主义市场经济的可持续健康发展, 又能正确处理好职业 外部的各种关系, 构建和谐社会。

总之, 从非营利组织自身的角度, 组织应该建立良好 的财务治理结构, 增加理事会财务人员的数量, 定期编制 财务报表, 这样不仅可以帮助组织做出更合理的决策, 也 有利于组织提高自身的公信力，从而筹集到更多的资金。 从政府的角度, 借助政府的宏观调控力量, 制定较为完善 的信息披露机制, 强化监事会的功能。 


\section{参考文献(References)}

[1] Zhongxin $\mathrm{Wu}$, "The formation and development of Modern Corporation financial governance theory", Accounting Research, no. 10, 2005.

[2] Guowang $\mathrm{Yu}$, "The analysis of financial governance of non-profit organization economic theory", Research on auditing and economic, no. 2,2007.

[3] Cao Yue and Zhao xibu, "Financial governance theory research review and Outlook", Financial accounting monthly, no. 13,2008 .

[4] Xiufang Zhao, "Analysis of the financial governance problems of public welfare non-profit organization", Friends of accounting, no. 4,2009.

[5] Ding Yue, "Financial governance of civil non-profit organizations", Journal of Zhengzhou Institute of Aeronautics Industry Management, vol. 29, no. 2,2011. 